\title{
SOME REFLECTIONS ON THE SAVARA'S ETHNOMEDICINE
}

\section{Madan Mohan}

\begin{abstract}
The article presents a description of magico-religious healers and herbalists, enumerating the various categories of specialists and their diagnostic methods. Likewise, the different causations attributed by them for illness are highlighted. The emphasis is on the strong belief in supernatural causation of illness and the significant role of the healer Kundan.
\end{abstract}

Key words: Buyya (religious head), Gamang (civil head of the village), healer, herbalist, Kundan (magico-religious healer), Kundanboi (female counterpart of Kundan), Savara

\section{INTRODUCTION}

This paper deals with the aspects of diagnosis and treatment in the realm of ethnomedicine among the Savara tribal community in the Srikakulam district of Andhra Pradesh. This ethnographic description, part of the health culture of the Kondh, attempts to record their indigenous knowledge system and show the relationship of health and disease related aspects with other facets of their culture (Majhi 2002).

The study is based on fieldwork, carried out during July and October 2003. In-depth data were obtained through the administration of semi-structured interview schedules as well as by the use of interview guides from the traditional medicine men and their patients. The distribution of the number of traditional health cures, provided in different villages in the Srikakulam district in Seethampeta Mandal of Andhra Pradesh, is discussed.

\section{PROFILE OF THE SAVARA COMMUNITY}

The Savara, being a noted tribe, are found inhabiting the Eastern Ghats of the Srikakulam and Vizianagaram districts. According to the 1991 census, the Savara population in Andhra Pradesh was 105,465. 
The Savaras usually live in settlements built on hill slopes, taking use of streams to facilitate easy access to podu and terrace fields, and for fetching water. Savaras speak their own language which belongs to the Kol Munda group of the Austro-Asiatic family of languages (Singh 1994).

The most significant feature regarding the social organization of the Savaras of Andhra Pradesh is the absence of a clan structure. For all practical social purposes, e.g., marriage, the group having a common surname is exogamous. Some sections of the Savaras of the Seethampet, Pathapatnam and Sompet areas have not even adopted family names. In the absence of exogamous family names and clans, they resort to inter-cousin marriages as a way to regulate their matrimonial alliances and thus avoid incest (Behera \& Pfeffer 1999).

Levirate, sororate and widow remarriages are socially approved. Four methods of acquiring mating partners are used - marriage by negotiations (Pankui), marriage by elopement (Dingdengboi), marriage by service (Kinersung) and marriage by exchange. Most of the Savara families are nuclear. Divorce is permitted on the grounds of impotency, continuous quarrels in the family, etc.

The Savaras subsist on agriculture. Savara agriculture consists of podu or shifting cultivation and terrace cultivation on hill slopes besides dry and wet farming. Savaras manufacture their own agricultural implements suited to their shifting, terrace, dry and wet farming. The tools are manufactured mostly by using indigenous techniques and locally available materials. Forest labour, collection and sale of non-timber forest produce, fishing and hunting are important subsidiary occupations.

Similar to most of the primitive societies, group cohesion and intra-tribal solidarity is maintained among the Savaras through social control institutions decreed by tradition (Boal 1997). There are three grades in the traditional leadership in social precedence, i.e. the Gamang, the Buyya and the Parja. The Gamang is the civic head of the village. The Buyya is the religious head and Savaras consider a Gamang to be rich with lands and other property. Desari, another religious functionary of the Savaras attends to the arranging of auspicious days for the performance of both social and religious ceremonies. The Kundan is also a religious functionary who recites hymns and conducts social and religious ceremonies. The festivals of the first eating of crops, propitiation of deities and ancestral spirits and the name-giving ceremony are some of the ritual functions at which the Kundan recites hymns, conducts the rituals and offers sacrifices. He chants hymns while playing on a musical instrument called kundan singrai. Kundanboi, the female counterpart of the Kundan, conducts birth deliveries, diagnoses and cures diseases. She is a soothsayer and employs magical charms as part of the curative prescription. 
Savaras propitiate various deities and ancestral spirits. The gods and spirit beings of the Savaras can be classified into benign and malign. The benevolent gods are those of earth, hill, pot, hearth, sun, rain, wind, stream etc. The malignant deities are associated with tigers, smallpox, bloodsuckers and sorcerers. There are as many malignant spirits as there are diseases known to the Savaras.

The Savaras draw certain designs on the walls known as Edising, also known as Lingor. These designs are drawn in honour of the dead, to avert the spread of disease and on the occasion of certain festivals. These Edising designs are common among the Savaras inhabiting interior hilly tracts. These drawings depict the moon, the sun, animals and all the objects which they come across in daily life.

\section{HEALTH PRACTITIONERS AMONG THE SAVARAS}

Health care is primarily provided by the relevant specialists:

1) magico-religious healers, and

2) the herbalists

While herbalists provide services for health promotion, prevention and curing of diseases, the magico-religious healers, on the other hand, render services only for the prevention and curing of disease. These practitioners deal with cases ranging from common ailments, e.g. the cold, minor surgeries due to accidents, to more serious health problems, such as treatment for snakebites, multiple fractures, individual organ-related conditions and specific diseases. They claim to have a holistic understanding of diseases and possess a wide variety of diagnostic techniques for disease control.

\section{The categories of different health practitioners and specialization}

While the magico-religious healers are generalists in the sense of their ability to diagnose and treat all types of illnesses, the herbalists claim to only diagnose and treat some specific ailments. The various types of specialists, identified among the herbalists in this field, are as follows:

1. Bone-setters: these are the ones who treat both simple and multiple bone fractures, in domestic animals and people.

2. Specialists regarding poisonous bites: they treat bites of snakes, insects, and animals such as dogs, rats, rabbits, etc. 
3. Specialists in specific diseases: their expertise lies in diagnosing and treating only some specific diseases or organ related illnesses. Thus, in the study area, specialists for fits, cataract, dental problems, leprosy, paralysis, joint pains, TB, jaundice, mental illness, and cancer are listed.

4. Specialists in paediatric diseases: the diseases specifically identified with children, e.g., swelling of the navel, diarrhoea, measles, rashes on the body, skin diseases are treated by some healers, and they claim to have a specialist status for their specialization in this regard.

5. Specialists for infertility, abortions, sterilization and increased sex drive: some herbalists claim to have special knowledge of fertilityrelated health issues commonly noticed in both men and women. They also deal with complicated deliveries and claim to be able to identify the sex of the foetus in the womb.

6. Traditional birth-attendants: the universal presence of birth attending mid-wives in each village depicts the hereditary trend of transmission of this art from one generation to another. Therefore, some women in each village acquire knowledge and skills of handling deliveries and give their services purely on a voluntary basis. As a reward, such women in every village are given some grain after the annual harvest.

\section{DIAGNOSIS OF ILLNESS}

\section{Magico-religious means. Diagnosis by the Kundan}

Members of the Savara community first approach the Kundanboi, a female magico-religious healer, available in each village to ascertain the cause of the illness. The Kundan is an aged male member of the community and a religious specialist who conducts every ritual during village festivals, being gifted with the skill of establishing contact with supernatural beings and seeking answers to the questions of the members in the community. When a patient or his/her family members approach him, the Kundan establishes contact with supernatural beings, the ancestral spirits, and even evil spirits to ascertain directly as to who among these could be the cause of the illness. He takes a few rice grains and, in a winnowing-fan, offers one grain to each of the beings, ancestral spirits and evil spirits and then puts the same grain into a small pot filled with water. If the grain floats on the water, the illness is attributed to that particular god/goddess, or ancestral spirit or evil spirit, in whose name that 
grain is put in to the pot. If the disease is attributed to any malevolent gods/ goddesses or evil spirits, the Kundan orders that he or she should leave the body soon. The healer diagnoses the cause of the illness through different methods - first, he would smell the body of the patient. If he feels some specific smell uncommon to the person, the illness is attributed to a malevolent goddess or evil spirit. Similarly, he would then look at the colour of the palm, the eyes, the tongue and also examine the patient's behaviour, provided the evil spirit or the malevolent goddess is found to be the cause of the illness.

\section{Diagnosis by herbalists}

The herbalists diagnose the exact cause of the disease by examining the natural factors, i.e. the eyes, skin and tongue colour, and also urine and sputum. Reading of the pulse is also very important. The herbalist would also examine the patient's behaviour, whether he/she is irritable or calm and composed, etc. All the herbalists also make a detailed note of the symptoms being experienced by the patients. On the basis of all these, the herbalists identify exactly which organ of the body is affected and for what reason. However, the intensity of the disease is established by resorting to a somewhat magical approach. They would root-out a plant to be used for the preparation of medicine for the supposed illness. If it is observed that the root of that plant is healthy and strong, then the intensity of the disease is considered minimal. Otherwise, the illness is believed to be acute. Relying on this test, the herbalists would make decisions with regard to the doses of medicine to be administered, and the length of the treatment period.

\section{Diagnosis of fractures by bonesetters}

The bonesetters resort only to physical examination to know whether there are multiple fractures or a single fracture, or whether it is just a dislocation of the bone.

\section{Diagnosis of poisonous bites}

The specialists of poisonous bites examine the pulse, eyes, and also the change of the skin colour in order to determine the severity of the bite. They determine the dosage of medicine according to the severity of a particular case. 


\section{TREATMENT}

\section{Magico-religious treatment by the Kundan}

After ascertaining the cause, making the supernatural being or spirit angry with the patient, the Kundan suggests an appropriate ritual and sacrifice to be made to appease this annoyed being or spirit. The intensity of the disease is believed to be commensurate with the intensity of anger of the being or spirit. In the case of high intensity of wrath of the being or spirit, causing severe and chronic diseases, he suggests the sacrifice of a large animal, for example, a goat, sheep, or pig. Similarly, in the case of low intensity of the anger, the Kundan proposes a normal sacrifice such as a black hen, a mouse, or a fish. The patient's family members promise to make the sacrifice within a given time. Then he gives some medicine, prepared from plants representing ancestral and supernatural spirits, for external application to the body. This medicine is expected to stop the aggravation of the disease before the prescribed sacrifice is made.

When the illness is identified to be due to an ancestral spirit, the Kundan orders the ancestral spirit to leave the patient's body immediately. If the ancestral spirit is reluctant to do this, the Kundan drives away the spirit by taking certain measures, e.g. beating him/her with a broomstick, throwing mustard seeds on to the patient, or by burning rubber.

After identifying the cause through one or all the means the Kundan prescribes the rituals and offerings to be made. If the illness is attributed to a benevolent god or goddesses, no animal sacrifices are prescribed; if it is attributed to ancestral spirits, or malevolent gods or goddesses, the sacrifice of a black chicken or a pigeon is prescribed along with a ritual to be conducted with flowers of seven different colours and other common ritual materials. In a situation where the illness is believed to be caused by an ancestral spirit, the Kundan will drive this away by adopting similar measures. However, if such means do not work in driving away the ancestral spirit from the patient's body, he will make an image of the ancestral spirit with mud and shoot an arrow into it, causing a serious injury so that the ancestral spirit leaves the body of the patient. If the illness is attributed to malevolent goddesses, a more elaborate ritual is prescribed by the Kundan. In this case, the healer takes the patient to the bank of a stream where he catches the goddess with his magical power, and then seals her in a small earthen pot and buries it in the ground or immerses in the stream. If magic/sorcery or a supernatural being is not held responsible for the illness, he will refer the patient to the herbalists. 
If the Kundan fails to identify any supernatural reason for the illness by himself, yet thinks that it could be because of some ancestral spirits, etc., he will refer the patient to a specialized magico-religious healer. Similarly, in the situation where the Kundan is sure that no supernatural agent or ancestral spirit is angry or that the illness is not caused by an ancestral spirit, or evil gods, he will refer the patient to an herbalist for proper treatment.

\section{Treatments by herbalists}

The herbalists prepare a variety of medicines using plants, animal products, insects, reptiles and birds. These products are distributed in different forms, e.g., syrups, tablets, and pastes for internal consumption and also in other formats such as oil, ointments, saps, ashes and powders for external application. Massage, as well as minor surgery, is also an important method of their treatment. Medicines, prepared from different parts of plants - roots, bark, leaves, flowers, seeds, fruits, and latex - have a predominant role in their treatment. For example, night blindness, julu jula pid-lue (glow worm), is treated with bananas.

Products of animals, insects, and birds used in different medicinal preparations include the following: eye of an owl, nail of a jackal/fox, teeth, flesh, milk, and moustache and bones of a tiger, and canines of a wild boar. Even human blood and urine are also used for the preparation of different medicines. In the case of fits, the blood ( $2-3$ drops) of the patient, mixed with medicine prepared from plant materials, is administered. In the case of snakebites, urine of the child below 12 years is given along with the latex of the arakha plant.

Ash prepared from the burning of cloth is used to stop bleeding injuries. The type of ash prepared by incinerating the dry leaves of plantain, along with the juice of plantain leaves, is applied to kill the penuka (lice) in hair.

The surgery includes the puncturing of the wounds to drain the pus, remove portions of flesh and skin due to wounds, corns, etc., using simple instruments such as a knife and a needle. The hair of the animals or the humans is also used for removing warts.

Massage is an important aspect of treatment in the case of many illnesses. There are some healers who claim to have special skills and knowledge with regard to massage. Various types of oil are used for different techniques of massage and for different complaints.

Bone setting is carried out by skilful resetting and by massaging the area with marrow extracted from beef bones. The fractured section is bandaged placing heated tobacco leaves on it and then using bamboo shards and thread 
to restrict the movement of the affected part. To quicken the healing, the bonesetters also apply drops of sap, a specific medicinal plant. These drops are put in the ear opposite to the fractured side of the patient's body.

Bandaging for cuts, boils and wounds to stop bleeding, is practiced by applying the gum prepared from the roots of talmuli and a piece of clean cloth.

While some plants and animal products can be collected and stored for ready use in the future, others need to be collected just prior to treatment. The herbalists do follow certain prescriptions and proscriptions in the collection of medicinal materials.

Some plants need to be collected only on the days of a lunar and solar eclipse. Sunday is believed to be the most auspicious day for collecting herbs and also for treatment. Thus, the herbalists most often collect the materials or prepare medicines from the materials collected on Sunday. Most of the patients also approach them on Sunday.

\section{Period of treatment}

The period of treatment in case of the magico-religious healers is only one day. Having detected the cause of illness, they prescribe a ritual and a sacrifice, which are generally conducted in consultation with the Disari.

Regarding the herbalists, the treatment may only last one day in the case of fits or poisonous bites. In the case of other illnesses, the herbalists normally give medicine for three days. If there is no relief from pain and suffering, inflicted by the disease or illness, medicine is given for an additional three-day period. There may be an extension for another three days, if suffering still persists. In any case, the health provider does not apply treatment for more than nine days.

When the herbalist fails to diagnose the disease, he refers the patient to the magico-religious healer or Kundan, who is more experienced than him, to detect the cause of illness once again. This time, the Kundan would confirm once again that the disease is not caused by evil spirits or that the supernatural beings are satisfied with the sacrifice and conduct of ritual as assured by the patient. Thereafter, according to the advice of the Kundan, the members approach another or the same herbalist for continuation of the treatment.

The Kundanboi or any other elderly woman of the village conducts the birth delivery. Generally on such occasions, all the men of the village are asked to leave the village except for two men who stand at a distance in order to be ready to help in an emergency. In the case of a difficult labour, one of the male members is sent to the Kundan or Buyya to fetch some medicine. If a woman is suffering from difficult labour either the Kundanboi or any elderly woman 
inserts a leaf in the hair of the suffering woman. It is claimed that as soon as the leaf is kept in the hair of the woman, delivery occurs without any further difficulty. It is very interesting to note that the Savara use their expertise in psychotherapy, as exemplified in the performance of the act of coconut-breaking intended to ensure easy delivery. In the psychological approach, the medicine-man stands outside the delivery enclosure and holds a coconut in his hand and chants some hymns. He orders loudly the delivery of the child as soon as he breaks the coconut. He purposefully delays the breaking of the coconut on the pretext of counting numbers $1,2,3$, and then breaks the coconut. As soon as the coconut is broken the woman usually delivers the baby.

If the delivery of the afterbirth is delayed, the Buyya, or the Kundan, is again approached for assistance. The Kundan gives the root of Vuttareni (Acharanthes aspersa) plant to be kept in the mouth of the woman thrice with the belief that the afterbirth may come out without any delay. The Kundanboi cuts the umbilical cord with a knife or an arrow-head and the placenta is buried in the outskirts of the village in a dung pit.

\section{CONCLUSION}

The study reveals that the magico-religious healers, as well as the herbalists, handle a wide range of illnesses among the Savara. Kundanboi, the female magico-religious healer, available in each village, plays a very important role in Savara society. It is to this person the members approach first and on the advice given they take health decisions. If the initial treatment fails and the illness is perceived serious they opt for the Kundan, a male magico-religious healer, to find the cause of the illness. The magico-religious healers, while prescribing rituals and sacrifices, may also suggest treatment from the herbalists.

The herbalists prepare a variety of medicines using plants, animal products, insects, reptiles and birds. These medications are in different forms, e.g., syrups, tablets and pastes for internal consumption, and also in forms such as oil, ointments, saps, ashes and powders for external application. Massage and minor surgery are also important methods of their treatment. Although the herbalists play an important role in health care their practice is intimately dependant on the magico-religious healers.

The health seeking often involves considerable shopping for both diagnosis and treatment. The shopping path is however not always unidirectional as the patients may go back to the health providers consulted earlier. 


\section{REFERENCES}

Behera, Deepak K. \& Pfeffer, Georg (eds.) 1999. Contemporary Society: Tribal Studies: Social Concern, Vol. 3. New Delhi: Concept Publishing Company.

Boal, Barbara M. 1997. Human Sacrifices and Religious Change: the Kondhs. New Delhi: Inter-India Publishing.

Majhi, J. 2002. (Unpublished thesis) Ethno-medicine: Practice and Practitioners. A Study among the Kondhs in Rayagada District of Orissa.

Singh, Kumar Suresh 1994. People of India:The Scheduled Tribes, Vol. 3. Delhi: Oxford University Press. 